\title{
PENGARUH KEPUASAN KERJA DAN LOYALITAS KERJA TERHADAP ORGANIZATIONAL CITIZENSHIP BEHAVIOR (OCB) PADA PEGAWAI BPKPAD DI MADINA
}

\author{
Ansori, Riri Mayliza \\ Sekolah Tinggi Ilmu Ekonomi "KBP" \\ ririmayliza@akbpstie.ac.id \\ ansorynst95@gmail.com
}

\begin{abstract}
This research was conducted in order to know the influence of job satisfaction and job loyalty to $O C B$. The data used in this study is the primary data obtained from the questionnaire. The number of samples in this study were 89 respondents taken using the slopin formula. The analytical technique used is multiple regersion and hypothesis test using $F$ test and $T$ test. The result showed that job satisfaction variable have positive and significant affect to $O C B$. The variable that has the most dominant influence on $O C B$ is work loyalty variable. From this research obtained $R$ value of 0,425 , it means that $42 \%$ OCB variable can be explained by independent variable that is job satisfaction and work loyalty and the rest that is equal to $58 \%$ explained by variables other then equation.
\end{abstract}

Keyword: job satisfaction, work loyalty, and $O C B$.

\section{PENDAHULUAN}

Dasar utama manejer dalam meningkatkan efektifitas perusahaan adalah perilaku sumber daya manusia (SDM) dalam bekerja. Yang dapat diwujudkan melalui interaksi kerja pada tingkat individual.

Perilaku organisasi cendrung melihat pegawai sebagai makhluk sosial yang memiliki kemampuan untuk berempati terhadap orang lain dan lingkungannya dan juga menyelaraskan nilai yang ada terhadap lingkungan yang ada di sekitarnya (Sloat, 1999) dalam jurnal (Vannecia Marchelle Soegandhi, Sutanto, \& S.Kom., MM., 2013).

OCB merupakan aktivitas individual yang unik dalam bekerja. Organisasi dapat terwujut ketika pegawai tidak hanya melakukan tugas pokoknya saja, akan tetapi bersedia memberikan waktu untuk menjalin hubungan kerja sama, saling membantu, menyampaikan masukan, aktif dalam organisasi, menunjukkan peyalanan yang baik pelanggan, dan memanfaatkan waktu yang diberikan degan baik.

Menurut Robbins dan Judge (2008:40) dalam jurnal (Rahmi, 2013), fakta menunjukkan bahwa organisasi yang mempunyai pegawai yang memiliki OCB yang baik, akan memberikan yang terbaik jika dilihat dari organisasi yang lain. 
Salah satu sebab pegawai melakukan perilaku OCB dikarenakan tingkat kepuasan kerjanya tercapai dan mereka merasa senang terhadap pekerjaannya. Untuk itu kepuasan kerja merupakan salah satu yang dapat menentukan OCB.

Menurut Susilo Martoyo (1992:115) dalam jurnal (Yuliana, H, \& Edward Gagah P.T., 2009), pada dasarnya merupakan salah satu aspek psikologis yang mencerminkan perasaan seseorang terhadap pekerjaannya, ia akan merasa puas dengan adanya kesesuaian antara kemampuan, keterampilan dan harapannya dengan pekerjaan yang ia hadapi.

Didalam suatu perusahaan akan membutuhkan pegawai yang memiliki loyalitas kerja tinggi untuk mengabdi sertamemberikan kontribusi besar kepada perusahaan.

Adanya perilaku OCB yang ditunjukkan oleh pegawai tak terlepas dari loyalitas yang dimilikinya. Loyalitas kerja berkaitan terhadap kesetiaan, kesetiaan dapat ditunjukkan daridorongan pegawai agar terus dalam bagian dari anggota perusahaan dan kesediaan pegawai berbakti dan menjaga perusahaan dalam menghadapi ancaman.

Dari fenomena diatas maka dapat disimpulkan bahwa perusahaan sangat perlu berfokus terhadap kesejahtraan pegawai, yang mampu mempengaruhi kepuasan kerja dan loyalitas kerja sehingga pegawai mampu memberikan kepada perusahaan kontribusi yang semaksimal mungkin.

Sehubungan dengan fenomenayang terjadi pada pegawai BPKPAD bahwa kurangnya partisifasi pegawai dalam sikap membantu antar sesama pegawai, hal ini dapat dibuktikan dari sebagian bidang yang ada di perusahaan ini bahwa sebagian pegawai yang telah menyelesaikan pekerjaannya lebih dahulu daripada pegawai yang lain, namun demikian tidak adanya rasa ingin membantu antara sesama mereka. Sebaliknya apabila pegawai memiliki sikap membantu antara sesama pegawai akan terciptakan hasil kerja yang baik.

Dari latar belakang masalah yang telah diuraikan, terdapat beberapa pertanyaan yang merupakan rumusan masalah dari penelitian ini yakni sebagai berikut:

1. Apakah kepuasan kerja berpengaruh terhadap Organizational Citizenship Behavior (OCB) pada pegawai Badan Pengelolaan Keuangan, Pendapatan dan Aset Daerah (BPKPAD) di Madina?.

2. Apakah loyalitas kerja berpengaruh secara terhadap Organizational Citizenship Behavior (OCB) pada pegawai Badan Pengelolaan Keuangan, Pendapatan dan Aset Daerah (BPKPAD) di Madina?

Penelitian ini diharapkan dapat memberikan manfaat bagi berbagai pihak, diantaranya :

1. Bagi pihak perusahaan

Kontribusi penelitian ini diharapkan dapat memberikan sumbangan pemikiran dalam hal peningkatan kinerja pegawai melalui kepuasan kerja dan pemberian loyalitas pegawai terhadap perilaku Organizational Citizenship Behavior (OCB) pada pegawai Badan Pengelolaan Keuangan, Pendapatan dan Aset Daerah (BPKPAD) di Madina.

2. Bagi peneliti 
Peneliti ini diharapkan dapat menjadi tambahan ilmu yang bermanfaat untuk dapat diterapkan di dunia kerja.

3. Bagi penelitian selanjutnya

Hasil dari penelitian ini diharapkan dapat memberikan kontribusi ilmu dalam hal pengembangan sumber daya manusia serta dapat dijadikan sebagai referensi bagi penelitian selanjutnya dengan topik yang sama.

\section{METODE PENELITIAN}

\section{Jenis Penelitian}

Jenis penelitian ini adalah Penelitian Kuantitatif. Pendekatan kuantitatif yaitu salah satu metode penelitian dimana data penelitian berupa angka-angka dan analisis menggunakan statistik (Sugiyono, 2015).

\section{Objek atau Lokasi Penelitian}

Menurut Sugiyono (2015) pengertian objek penelitian adalah sasaran ilmiah untuk mendapatkan data dengan tujuan dan kegunaan tertentu tentang sesuatu hal objektif, valid, dan reliabel. Dengan demikian, objek penelitian merupakan lokasi dimana untuk mendapatkan sejumlah data yang akan dilakukan penelitian. Badan Pengelolaan Keuangan, Pendapatan dan Aset Daerah yang akan dijadikan sebagai objek penelitian ini yang beralamat di Mandailing Natal.

\section{Populasi dan Sampel}

\section{a. Populasi}

Populasi dari penelitian ini adalah seluruh pegawai pada BPKPAD yang berjumlah 115 orang pada tahun 2017.

\section{b. Sampel}

Jumlah sampel pada penelitian ini ditetapkan sejumlah 89 responden. Peneliti menentukan jumlah sampel dengan menggunakan metode slovin. $\mathrm{n}=\mathrm{N} /\left(1+\mathrm{N} \mathrm{e}^{2}\right)=115 /\left(1+115 \times 0,05^{2}\right)=89,3203883 \gg 89$

Dengan demikian, jumlah sampel yang dibutuhkan dalam penelitian ini adalah 89 pegawai.

\section{c. Teknik Pengambilan Sampel}

-Sampling Purposive

\section{Jenis dan Sumber Data}

Jenis data yang digunakan

a. Jenis Data

1. Data Kualitatif

Data yang dinyatakan dalam bentuk kata-kata atau bukan dalam bentuk angka

2. Data Kuantitatif

Data yang dinyatakan dalam bentuk angka. Merupakan hasil dari perhitungan dan pengukuran.

b. Sumber Data

1. Data Primer

Data primer ini data yang dikumpulkan dan diolah sendiri oleh peneliti langsung dari responden berupa kuesioner yang disebarkan.

2. Data Sekunder 
Data sekunder merupakan data yang diperoleh tidak langsung oleh pengumpul data, melainkan memperoleh data dari pihak lain atau lewat dokumen yang ada.

\section{Teknik Pengumpulan Data}

\section{a. Kuisioner}

Kuisioner merupakan teknik pengumpulan data yang dilakukan dengan cara memberi beberapa pertanyaan atau pernyataan tertulis kepada responden untuk dijawabnya (Sugiyono, 2015).

\section{b. Interview}

Interview adalah teknik pengumpulan data dari permasalahan yang harus diteliti dan apabila ingin mengetahui hal-hal dari responden secara mendalam dan jumlah respondennya kecil (Sugiyono, 2015).

\section{Analisis Regresi Berganda}

Analisis regresi linier berganda bermaksud meramalkan bagaimana keadaan (naik turunnya) variabel dependen, bila dua atau lebih variabel independen sebagai faktor prediktor dimanipulasi (dinaik turunkan nilainya). Jadi analisis regresi berganda akan dilakukan bila jumlah variabel independennya minimal 2 (Sugiyono, 2013).

Analisis regresi berganda merupakan untuk mengetahui hubungan antara variabel independen dan variabel dependen.

$\mathrm{Y}=\alpha+\beta 1 \mathrm{X} 1+\beta 2 \mathrm{X} 2+\mathrm{e}$

$\mathrm{Y}=$ Organizational Citizenship Behavior

$\mathrm{X} 1=$ Kepuasa kerja

X2 = Loyalitas Kerja

$\alpha=$ Koefisien Konstanta

$\beta 1=$ Koefisien regresi untuk Kepuasan Kerja

$\beta 2=$ Koefisien untuk Loyalitas Kerja

$\mathrm{e}=$ Standar error

\section{Uji Hipotesis}

1. Jika nilai signifikan > 0,05 maka hipotesis ditolak (koefisien regresi tidak signifikan). Ini berarti secara parsial variabel independen tidak mempunyai pengaruh secara signifikan terhadap variabel dependen.

2. Jika nilai signifikan $\leq 0,05$ maka hipotesis diterima (koefisien regresi signifikan ). Ini berarti secara parsial variabel independen tersebut mempunyai pengaruh yang signifikan terhadap variabel dependen. 
HASIL PENELITIAN

\section{Teknik Analisis Data}

Tabel 1

Uji Validitas

\begin{tabular}{|c|c|c|c|}
\hline Variabel & IndikatorSoal & R Hitung & Keterangan \\
\hline \multirow{12}{*}{$\mathrm{X} 1$} & G1 & 0.584 & Valid \\
\hline & G2 & 0.531 & Valid \\
\hline & G3 & 0.442 & Valid \\
\hline & P1 & 0.392 & Valid \\
\hline & $\mathrm{P} 2$ & 0.371 & Valid \\
\hline & P3 & 0.384 & Valid \\
\hline & PP1 & 0.432 & Valid \\
\hline & PP2 & 0.392 & Valid \\
\hline & PP3 & 0.529 & Valid \\
\hline & R1 & 0.511 & Valid \\
\hline & R2 & 0.519 & Valid \\
\hline & R3 & 0.354 & Valid \\
\hline \multirow{8}{*}{$\mathrm{X} 2$} & MR1 & 0.317 & Valid \\
\hline & MR2 & 0.555 & Valid \\
\hline & MP1 & 0.515 & Valid \\
\hline & MP2 & 0.524 & Valid \\
\hline & $\mathrm{T} 1$ & 0.664 & Valid \\
\hline & $\mathrm{T} 2$ & 0.545 & Valid \\
\hline & ST1 & 0.491 & Valid \\
\hline & ST2 & 0.588 & Valid \\
\hline \multirow{15}{*}{$\mathrm{Y} 1$} & AL1 & 0.551 & Valid \\
\hline & AL2 & 0.605 & Valid \\
\hline & AL3 & 0.581 & Valid \\
\hline & CN1 & 0.320 & Valid \\
\hline & CN2 & 0.381 & Valid \\
\hline & $\mathrm{CN} 3$ & 0.546 & Valid \\
\hline & $\mathrm{CO} 1$ & 0.593 & Valid \\
\hline & $\mathrm{CO} 2$ & 0.592 & Valid \\
\hline & $\mathrm{CO} 3$ & 0.446 & Valid \\
\hline & SP1 & 0.592 & Valid \\
\hline & SP2 & 0.538 & Valid \\
\hline & SP3 & 0.439 & Valid \\
\hline & CV1 & 0.620 & Valid \\
\hline & CV2 & 0.438 & Valid \\
\hline & CV3 & 0.446 & Valid \\
\hline
\end{tabular}

Dari tabel diatas telah dapat menunjukkan bahwa semua item pernyataan yang digunakan untuk mengukur variabel-variabel yang digunakan dalam penelitian ini mempunyai koefisien korelasi yang lebih besar dari $r$ tabel. Dari hasil tersebut menunjukkan bahwa semua item pernyataan (indikator) adalah valid. Dimana hasil tersebut berdasarkan kolom Corected Item-Total Correlation. (dikatan Valid apabila nilainya $>0,30$ )

Tabel 2

Uji reabilitas

\begin{tabular}{|c|c|c|c|}
\hline Variabel & Cronbach Alpha & $\begin{array}{c}\text { Standar } \\
\text { Reliabilitas }\end{array}$ & Keterangan \\
\hline $\begin{array}{c}\text { Kepuasan Kerja } \\
(\mathrm{X} 1)\end{array}$ & 0,727 & 0,60 & Reliabel \\
\hline $\begin{array}{c}\text { Loyalitas Kerja } \\
(\mathrm{X} 2)\end{array}$ & 0,744 & 0,60 & Reliabel \\
\hline \begin{tabular}{c} 
Organizational Citizenship Behavior (Y1) \\
\hline
\end{tabular} & 0,740 & 0,60 & Reliabel \\
\hline
\end{tabular}

Berdasarkan hasil dari uji reliabel tersebut menunjukkan bahwa semua variabel memiliki nilai Cronbach Alpha yang lebih besar dari 0,60 sehingga dapat 
disimpulkan bahwa item-item pertanyaan dari kuesioner Kepuasan Kerja, Loyalitas Kerja dan Orgnizational Citizenship Behavior (OCB) yang dapat dinyatakan reliabel yang dapat disimpulkan bahwa kuesioner layak digunakan sebagai alat ukur.

\section{Uji (TCR)}

Tabel 3

Tanggapan Responden Terhadap Kepuasan Kerja

\begin{tabular}{|c|c|c|c|c|c|}
\hline No & Variabel & $\begin{array}{c}\text { Jumlah } \\
\text { Responden }\end{array}$ & Rata-Rata Skor & TCR\% & Kriteria \\
\hline 1 & Item 1 & 89 & 4.44 & 70,6 & Baik \\
\hline 2 & Item2 & 89 & 4.42 & 73,6 & Baik \\
\hline 3 & Item3 & 89 & 4.43 & 81,0 & Sangat baik \\
\hline 4 & Item4 & 89 & 3,87 & 78,6 & Baik \\
\hline 5 & Item5 & 89 & 3,98 & 60,3 & Kurang baik \\
\hline 6 & Item6 & 89 & 4.11 & 55,3 & Kurang baik \\
\hline 7 & Item7 & 89 & 4,33 & 57,9 & Kurang baik \\
\hline 8 & Item8 & 89 & 4,08 & 71,1 & Baik \\
\hline 9 & Item9 & 89 & 4,22 & 57,9 & Kurang baik \\
\hline 10 & Item10 & 89 & 3,94 & 64,6 & Baik \\
\hline 11 & Item11 & 89 & 4,01 & 63,1 & Baik \\
\hline 12 & Item12 & 89 & 3,96 & 62,0 & Baik \\
\hline \multicolumn{2}{|l}{ Nilai Rata-Rata Kepuasan Kerja Pegawai } & 4,15 & 66,33 & Baik \\
\hline
\end{tabular}

Dari tabel di atas maka dapat dilihat bahwa kesimpulan dari tanggapan responden terhadap variabel kepuasan kerja berada pada tingkatankeempat (Baik), yaitu 66,33 yang terletak pada $61 \%$ sampai dengan $80 \%$.

\section{Tabel 4}

Tanggapan Responden Terhadap Loyalitas Kerja

\begin{tabular}{|c|c|c|c|c|c|}
\hline No & Variabel & Jumlah Responden & Rata-Rata Skor & $\underset{\%}{\text { TCR }}$ & Kriteria \\
\hline 1 & Item1 & 89 & 4,03 & 55,5 & Kurang Baik \\
\hline 2 & Item2 & 89 & 3,93 & 68,8 & Baik \\
\hline 3 & Item3 & 89 & 4,10 & 69,2 & Baik \\
\hline 4 & Item4 & 89 & 4,15 & 59,4 & Kurang Baik \\
\hline 5 & Item5 & 89 & 4,02 & 69,0 & Baik \\
\hline 6 & Item6 & 89 & 4,13 & 56,8 & Kurang Baik \\
\hline 7 & Item7 & 89 & 3,81 & 58,1 & Kurang Baik \\
\hline 8 & Item8 & 89 & 4,01 & 57,4 & Kurang Bik \\
\hline \multicolumn{3}{|c|}{ Nilai Rata-Rata Loyalitas Kerja Pegawai } & 4,02 & 61,77 & Baik \\
\hline
\end{tabular}

Maka dapat dilihat bahwa kesimpulan dari tanggapan responden terhadap variabel loyalitas kerja berada pada tingkat keempat (Baik), yaitu 61,77 yang terletak pada $61 \%$ sampai dengan $80 \%$. 
Tabel 5

Tanggapan Responden Terhadap OCB

\begin{tabular}{|c|c|c|c|c|c|}
\hline No & Variabel & Jumlah Responden & Rata-Rata Skor & $\begin{array}{c}\text { TCR } \\
\text { \% }\end{array}$ & Kriteria \\
\hline 1 & Item1 & 89 & 4,18 & 57,5 & Kurang Baik \\
\hline 2 & Item2 & 89 & 3,89 & 66,5 & Baik \\
\hline 3 & Item3 & 89 & 3,76 & 81,2 & Bangat Baik \\
\hline 4 & Item4 & 89 & 4,18 & 65,0 & Kurang Baik \\
\hline 5 & Item5 & 89 & 4,49 & 50,3 & Kurang Baik \\
\hline 6 & Item6 & 89 & 4,08 & 70,7 & Baik \\
\hline 7 & Item7 & 89 & 3,66 & 71,7 & Baik \\
\hline 8 & Item8 & 89 & 3,91 & 58,8 & Kurang Baik \\
\hline 9 & Item9 & 89 & 4,17 & 54,2 & Kurang Baik \\
\hline 10 & Item10 & 89 & 3,96 & 69,5 & Baik \\
\hline 11 & Item11 & 89 & 3,74 & 70,3 & Baik \\
\hline 12 & Item12 & 89 & 3,83 & 63,0 & Baik \\
\hline 13 & Item13 & 89 & 3,78 & 54,8 & Baik \\
\hline 14 & Item14 & 89 & 4,13 & 3,99 & Kurang Baik \\
\hline 15 & Item15 & 89 & Baik & Baik \\
\hline
\end{tabular}

Maka dapat dilihat bahwa kesimpulan dari tanggapan responden terhadap variable OCB berada pada tingkat keempat (Baik), yaitu 64,78 yang terletak pada $61 \%$ sampai dengan $80 \%$.

\section{Uji Asumsi Klasik}

Tabel 6

Uji Normalitas

One-Sample Kolmogorov-Smirnov Test

\begin{tabular}{|ll|r|}
\hline & & \multicolumn{1}{|c|}{ Standardized Residual } \\
\hline $\mathrm{N}$ & & 89 \\
Normal & Mean & .0000000 \\
Parameter & Std. Deviation & \\
$\mathrm{s}^{\mathrm{a}}$ & & .98857105 \\
Most $\quad$ Absolute & & .086 \\
Extreme & Positive & .068 \\
Difference & Negative & -.086 \\
$\mathrm{~s}$ & & .813 \\
Kolmogorov-Smirnov Z & .523 \\
\hline Asymp. Sig. (2-tailed) & & \\
\hline
\end{tabular}

a. Test distribution is Normal.

Dengan data yang dapat dilihat berdasarkan hasil olahan data di atas bahwa nilai sig sebesar 0,523 $>0,05$. Sehingga dapat ditarik kesimpulan bahwa data yang diolah berdistribusi normal. 
Uji Multikonearitas

Tabel 7

Uji VIF

Coefficients $^{\mathrm{a}}$

\begin{tabular}{|l|r|r|}
\hline \multirow{2}{*}{ Model } & \multicolumn{2}{|c|}{ Collinearity Statistics } \\
\cline { 2 - 3 } 1 (Constant) & Tolerance & \multicolumn{2}{|c|}{ VIF } \\
KK : Kepuasan Kerja & .824 & \\
& & \\
LK : Loyalitas Kerja & .824 & 1.213 \\
& & 1.213 \\
\hline
\end{tabular}

a. Dependent Variable: OCB :

Organizational Citizenship Behavior

Berdasarkan uji multikolinearitas bahwa menunjukkan nilai tolerance dari setiap variabel bebas berada di atas 0,1 yaitu 0,824 dan nilai VIF berada dibawah 10 yaitu 1.213 . hal ini dapat membuktikan bahwa tidak adanya multikolinearitas pada variabel bebas.

Tabel 8

Linearitas (X1)

ANOVA Tabel

\begin{tabular}{|c|c|c|}
\hline & & Sig. \\
\hline $\begin{array}{l}\text { OCB : } \\
\text { Organizartional } \\
\text { Citizenship } \\
\text { Behavior * KK : } \\
\text { Kepuasan Kerja }\end{array}$ & $\begin{array}{l}\text { Betwee (Combined) } \\
\mathrm{n} \\
\text { Groups Linearity } \\
\quad \text { Deviation from Linearity } \\
\text { Within Groups } \\
\text { Total }\end{array}$ & $\begin{array}{l}.004 \\
.000 \\
.096\end{array}$ \\
\hline
\end{tabular}

Berdasarkan nilai signifikan : dapat dilihat dari hasil olahan data diatas bahwa dapat diperoleh nilai signifikan $=0,096$ lebih besar dari 0,05 yang artinya terdapat hubungan linear secara signifikan antara variabel Kepuasan Kerja (X1) terhadap OCB (Y).

Tabel 9

\section{Linearitas (X2)}

ANOVA Tabel

\begin{tabular}{|c|c|c|}
\hline & & Sig. \\
\hline $\begin{array}{l}\text { OCB : } \\
\text { Organizartiona } \\
1 \text { Citizenship } \\
\text { Behavior * LK } \\
\text { : Loyalitas } \\
\text { Kerja }\end{array}$ & $\begin{array}{l}\text { Between } \text { (Combined) } \\
\text { Groups } \\
\quad \text { Linearity } \\
\text { Deviation from Linearity } \\
\text { Within Groups } \\
\text { Total }\end{array}$ & $\begin{array}{l}.000 \\
.000 \\
.332\end{array}$ \\
\hline
\end{tabular}


Berdasarkan nilai signifikan : dapat dilihat dari hasil olahan data diatas bahwa dapat diperoleh nilai signifikan $=0,332$ lebih besar dari 0,05 yang artinya terdap hubungan linear secara signifikan antara variabel Loyalitas Kerja (X2) terhadap OCB (Y).

\section{Heteroskedastisitas}

Uji Metode Grafik

\section{Scatterplot}

Dependent Variable: OCB : Organizational Citizenship Behavior

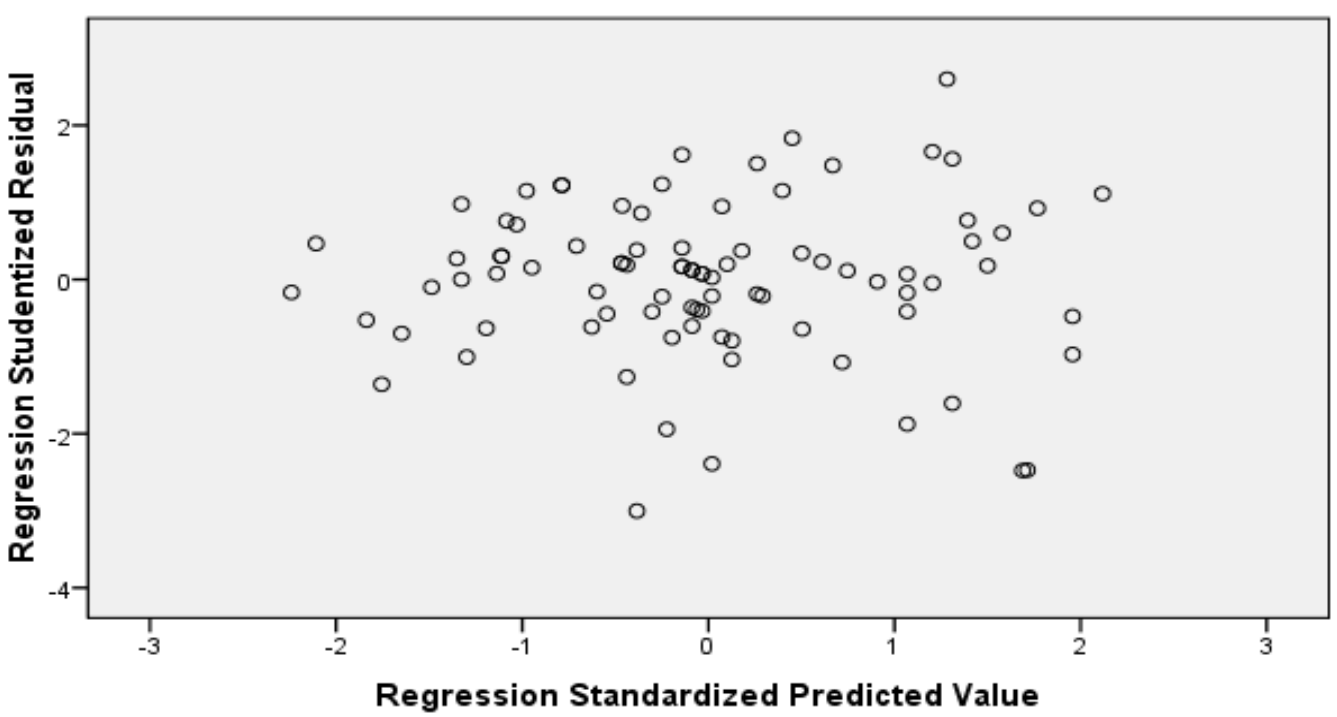

Dari diagram scatterplot pada gambar di atas terlihat bahwa plot menyebar secara tidak teratur atau tidak berpola, serta titik-titik yang menyebar di atas dan di bawah 0 atau sumbu $\mathrm{Y}$, ini dapat membuktikan bahwa tidak terjadinya heteroskedastisitas. sehingga dapat disimpulkan bahwa model regresi tidak mengandung masalah heteroskedastisitas

\section{Analisis Regresi Berganda}

\section{Tabel 10 \\ T-Test (Uji t statistik)}

Coefficients $^{\mathrm{a}}$

\begin{tabular}{|l|r|r|}
\hline Model & $\mathrm{t}$ & \multicolumn{1}{|c|}{ Sig. } \\
\hline $1 \quad$ Constant) & 2.557 & .012 \\
KK : Kepuasan Kerja & 1.643 & .104 \\
LK : Loyalitas Kerja & 6.602 & .000 \\
\hline
\end{tabular}

a. Dependent Variable: OCB :

b. Organizational Citizenship Behavior

Berdasarkan pada tabel diatas dengan menggunakan uji $\mathrm{T}$, maka dapat dilihat dari masing-masing pengaruh dari variabel Kepuasan Kerja dan Loyalitas 
Kerja dari tingkat signifikan (probabilitas). Jika tingkat signifikannya kecil dari 0,05 maka hipotesis ditolak( koefisien regresi tidak signifikan ) sebaliknya jika nilai signifikan $<0,05$ maka hipotesis diterima ( koefisien regresi signifikan ). Dari tabel diatas menunjukkan bahwa variabel kepuasan kerja tidak berpengaruh signifikan terhadap OCB karena nilai signifikan > dari 0,05 yaitu 0,104, sedangkan variabel loyalitas kerja berpengaruh signifikan terhadap OCB karena < dari 0,05 yaitu 0,000 .

\section{Tabel 11}

Uji R $\mathbf{R}^{2}$ (R Square)

Model Summary

\begin{tabular}{|l|r|r|r|r|}
\hline Model & $\mathrm{R}$ & R Square & $\begin{array}{c}\text { Adjusted } \mathrm{R} \\
\text { Square }\end{array}$ & $\begin{array}{c}\text { Std. Error of the } \\
\text { Estimate }\end{array}$ \\
\hline 1 & $.662^{\mathrm{a}}$ & .439 & .425 & 4.16342 \\
\hline
\end{tabular}

a. Predictors: (Constant)

b. LK : Loyalitas Kerja,

c. KK : Kepuasan Kerja

Uji koefisien determinasi untuk mengetahui seberapa erat pengaruh kepuasan kerja dan loyalitas kerja terhadap OCB pegawai. Berdasarkan hasil olah data menggunakan spss didapatkan nilai koefisien determinasi R2 sebesar 0,425 hal ini menunjukkan bahwa sebesar $42 \%$ OCB pada pegawai BPKPAD dipengaruhi oleh variasi kedua variabel independent yang digunakan, yaitu kepuasan kerja dan loyalitas kerja sedangkan sisanya dipengaruhi oleh faktor lain dari penelitian ini.

Tabel 12

Goodness Of Fit (F Statistik atau F Test)

$\operatorname{ANOVA}^{\mathrm{b}}$

\begin{tabular}{|ll|r|r|}
\hline Model & F & \multicolumn{1}{|c|}{ Sig. } \\
\hline $1 \quad \begin{array}{l}\text { Regression } \\
\text { Residual } \\
\text { Total }\end{array}$ & 33.587 & $.000^{a}$ \\
\hline
\end{tabular}

a. Predictors: (Constant),

LK : Loyalitas Kerja,

KK : Kepuasan Kerja

b. Dependent Variable:

OCB : Organizational

Citizenship Behavior

Dari hasil analisis regresi dapat diketahui bahwa secara bersama-sama variabel independen memiliki pengaruh yang signifikan terhadap variabel dependen. Hal ini dapat dibuktikan dari nilai F hitung sebesar 33.587 dengan nilai signifikansi (sig) sebesar 0,000 Karena nilai signifikansi (sig) jauh lebih kecil dari 0,05 bahwa kepuasan kerja dan loyalitas secara bersama-sama berpengaruh terhadap OCB. Sehingga hipotesis yang menyatakan bahwa kepuasan kerja dan loyalitas secara bersama-sama berpengaruh positif terhadap OCB dapat diterima. 


\section{SIMPULAN}

Berdasarkan hasil analisis dan pembahasan yang dilakukan, maka dapat disimpulkan yang dapat diambil adalah Loyalitas Kerja dalam BPKPAD memiliki pengaruh signifikan terhadap OCB berdasarkan persepsi pegawai. Hasil dari analisis, diperoleh hasil bahwa kepuasan kerja dengan indikator ( gaji, pekerjaan itu sendiri, program pengembangan SDM dan rekan kerja), dan loyalitas kerja dengan indikator (menjaga rahasia bisnis organisasi, menaati peraturan organisasi, toleransi, sikap tanggap lingkungan) memberikan pengaruh terhadap OCB dalam perusahaan. Dengan demikian, hipotesis yang diajukan terbukti.

Kepuasan Kerja dan Loyalitas Kerja berpengaruh secara simultan terhadap OCB. Hal ini dapat dibuktikan dari hasil determinasi yakni sebesar 43\% OCB dipengaruhi oleh variasi kedua variabel yang digunakan dalam penelitian, sisanya adalah faktor lain. Loyalitas Kerja lebih dominan berpengaruh terhadap OCB. Hal ini dibuktikan dengan koefisien regresi Loyalitas Kerja lebih besar dibanding Kepuasan Kerja berdasarkan dari penelitian yang peneliti lakukan pada perusahaan BPKPAD.

\section{DAFTAR PUSTAKA}

Aldi, Y., \& Susanti, F. (2019). Pengaruh Stress Kerja Dan Motivasi Kerja Terhadap Prestasi Kerja Karyawan Pada PT. Frisian Flag Indonesia Wilayah Padang. https://doi.org/10.31227/osf.io/et4rn

Fendi, Z., \& Susanti, F. (2018). Pengaruh Kepuasan Kerja Terhadap Turnover Intention Dengan Komitmen Organisasi Sebagai Variabel Intervening Pada CV. Belibis Pariaman. https://doi.org/10.31227/osf.io/wumgx

H.Teman Koesmono. (2005). Pengaruh Budaya Organisasi Terhadap Motivasi Dan Kepuasan Kerja Serta Kinerja Karyawan Pada Sub Sektor Industri Pengolahan Kayu Skala Menengah Di Jawa Timur. Jurnal Manajemen, 7, pp.171-188. https://doi.org/10.9744/jmk.7.2.pp. 171-188

Handara, M. G. D., \& Mujiati2, N. W. (n.d.). Pengaruh motivasi dan gaya kepemimpinan terhadap kepuasan kerja karyawan pada PT Jasa Raharja (Persero)cabang bali. Jurnal Manajemen, 1569-1584.

Lubis, A. Y. O., \& Susanti, F. (2019). Pengaruh Gaya Kepemimpinan Dan Kompensasi Terhadap Prestasi Kerja Karyawan (Studi pada PT Japfa Comfeed Indonesia (JCI) Tbk Devisi Fam 1. https://doi.org/10.31227/osf.io/7tbrg

Junaidi, R., \& Susanti, F. (2019). Pengaruh Gaya Kepemimpinan Dan Budaya Organisasi Terhadap Kinerja Pegawai Pada UPTD Baltekkomdik Dinas Pendidikan Provinsi Sumatera Barat. https://doi.org/10.31227/osf.io/bzq75

Malik, A. (2014). Pengaruh Budaya Organisasi dan Loyalitas Kerja Dengan 
Intensi Turnover Pada Karyawan PT. Cipaganti Heavy Equipment Samarinda. Jurnal Manajemen, 2(1), 65-75.

Mayasari, D. L., Nurhardjo, B., \& Sunardi. (2006). Pengaruh Motivasi Kerja , Loyalitas Kerja Terhadap Karyawan Pada Kantor Balai Pengelolaan Daerah Influence Of Work Motivation, Loyalty Towards Work Organizational Citizenship Behavior ( Ocb ) And Performance Of Hall Sampean Watershed Management In Bondow. Jurnal Manajemen.

Mayliza, R. (2019). Pengaruh Konflik Dan Kejenuhan Terhadap Kepuasan Kerja Karyawan PT. PLN (Persero) Sektor Pembangkitan Dan Pengendalian Pembangkitan Ombilin. https://doi.org/10.17605/OSF.IO/DQZ3K

Prabu, A. (2005). Pengaruh motivasi terhadap kepuasan kerja pegawai badan koordinasi keluarga berencana nasional Kabupaten Muara Enim. Jurnal Manajemen, 3(6), 1-25.

Rahmi, B. M. (2013). Pengaruh Kepemimpinan Transformasional terhadap Organizational Citizenship Behavior dan Kepuasan Kerja (Studi pada Guru Tetap SMA Negeri di Kabupaten Lombok Timur). Jurnal Manajemen, 330-350.

Ridho, M., \& Susanti, F. (2019). Pengaruh Stres Kerja Dan Motivasi Kerja Terhadap Kepuasan Kerja Pada Karyawan Bank Mandiri Syariah Cabang Padang. https://doi.org/10.31227/osf.io/pa2cg

Setyobudi, S. B. (2015). Pengaru Kepuasan Kerja, Motivasi Dan Loyalitas Kerja Terhadap Organizational Citizenship Behavior (Ocb) Karyawan Pada Pt. Benih Citra Asia Jember. Jurnal Manajemen, 1-70.

Setyobudi, S. B., Prihatini, D., \& Paramu, H. (n.d.). Pengaruh Kepuasan Kerja, Motivasi Dan Loyalitas Kerja Terhadap Organizational Citizenship Behavior (OCB) Karyawan Pada Pt. Benih Citra Asia Jember. Jurnal Manajemen.

Sugiyono. (2015). Statistik Nonparametris Untuk Penelitian. Book. Bandung: CV. Alvabeta.

Triyanto, A. (2009). Organizational Citizenship Behavior ( OCB ) Dan Pengaruhnya Terhadap Keinginan Keluar dan Kepuasan Kerja Karyawan. Jurnal Manajemen, 7(4), 1-13.

Vannecia Marchelle Soegandhi, D. E. M., Sutanto, M. S. dan R. S., \& S.Kom., Mm., M. (2013). Pengaruh Kepuasan Kerja Dan Loyalitas Kerja Terhadap Organizational Citizenship Behavior Pada Karyawan Pt . Surya Timur Sakti Jatim. Jurnal Manajemen, 1(1). 
Yasa, I. P. S., \& Mudiartha, I. W. utama. (n.d.). Pengaruh kompensasi dan lingkungan kerja terhadap kepuasan kerja dan kinerja karyawan pada karma jimbaran. Jurnal Manajemen, 609-623.

Yudistira, D. S., \& Susanti, F. (2019). Pengaruh Motivasi Kerja Dan Budaya Kerja Terhadap Kinerja Karyawan Dinas Pemberdayaan Masyarakat Dan Desa, Pengendalian Penduduk Dan Keluarga Berencana Kabupaten Pesisir Selatan. https://doi.org/10.31227/osf.io/jk54m

Yuliana, M., H, L. B., \& Edward Gagah P.T. (2009). Pengaruh lingkungan kerja, disiplin kerja, dan kepuasan kerja terhadap kinerja karyawan bmt taruna sejahtera ungaran. Jurnal Manajemen. 